\title{
JEAN BAUDRILLARD: REFLEXIONES SOBRE LA HISTORIA Y EL TIEMPO A FIN DE SIGLO
}

\author{
María José Clavo
}

\section{Introducción: Modernidad-postmodernidad}

Antes de introducirnos en las ideas de Baudrillard en torno al tiempo y la historia creo interesante situar a nuestro autor en el contexto de la crítica a la modernidad desde el que podremos encontrar un sentido más amplio para ellas.

Tres grandes ideas obsesionan, vertebran y definen la modernidad:

1. La concepción de la historia en términos de progreso: la ciencia hace posible el progresivo conocimiento, control y dominio de la realidad al servicio del hombre, y ello de un modo imparable.

2. El descubrimiento de la razón autónoma como "medida" de todas las cosas y, en consecuencia, la necesidad de una legitimación y fundamentación de la misma, que se entiende como autolegitimación y autofundamentación, precisamente en virtud de la autonomía de la racionalidad.

3. El protagonismo del sujeto. La negación de toda subordinación de la razón a instancias trascendentes, junto con la obsesiva preocupación por la certeza, conduce a la subjetividad, trascendental o absoluta, a desempeñar un papel central en el conocimiento.

La filosofía moderna se presenta construida sobre el sujeto como referente último, por ello éste es considerado autor de la historia (entendida como un camino de autoconciencia progresiva $y$, por lo tanto, como un camino de liberación), capaz de elaborar la objetividad científica, ser fuente de normatividad ética y llevar a cabo la crítica racional de las ideas.

A lo largo del proceso histórico-epistemológico que conduce de la modernidad a su crítica destaca como decisiva la reflexión de Max Weber que pretende ser una toma de conciencia desenmascaradora de lo que se esconde detrás de la liberación, entendida como una progresiva racionalización. La llus- 
tración es el triunfo de la razón instrumental, lo que supone una reificación de la realidad, incluido el ser humano, que nos conduce a un mundo en el que el hombre se encuentra sometido a un tipo de esclavitud sutil pero profunda.

La Escuela de Francfort recoge la teoría weberiana y, a partir de ella, denuncia las contradicciones que se encierran en nuestra sociedad libre y democrática.

Lo fundamental de la crítica a la modernidad se basa en la autocrítica de la razón. El modelo teórico ilustrado exigía legitimación racional y universalidad. La dialéctica de la llustración muestra la paradoja interna de la razón moderna que teniendo estas exigencias es, sin embargo, conciencia del tiempo y de su inserción histórica. La necesidad de seguridad y dominio de la razón ilustrada le conduce a la búsqueda desesperada de fundamentaciones últimas y, puesto que ha roto con toda instancia fundante trascendente, no le queda otra salida que tener que darse a sí misma su propia fundamentación y legitimidad: la razón se funda a sí misma. Pero hablar de sí misma para legitimarse es hacer mitología. Esta idea es la raiz de la crisis de la autoconciencia postmoderna de la razón.

La postmodernidad cuestiona la autotrascendencia de la razón, en consecuencia lleva a cabo una actividad deconstructiva que deja al descubierto lo que hay de irracional tras las viejas nociones modernas. Con ello relativiza los pilares de la cultura de la modernidad y debilita los referentes de lo real en que creían los modernos: historia, sujeto y razón. Esta conciencia falibilista de lo que se ha creido sustancial y decisivo para la estructura formal de la realidad es lo que se llama nihilismo.

La postmodernidad significa una toma de conciencia desesperanzada de nuestra situación presente que constata el fracaso del proyecto ilustrado, como un proyecto de progresiva liberación del hombre a través de los ejes de la historia y la razón.

Se caracteriza, entonces, por un profundo escepticismo frente a la razón instrumental y al positivismo cientificista; se cuestiona la aparente neutralidad de la ciencia y la técnica; se niega que exista una fundamentación final, por lo que rechaza la razón totalizante, el universalismo y la metafísica.

En su lugar se constituye en una razón "situada", un pensamiento que se asigna a sí mismo la tarea de mostrar la importancia de lo singular, la diferencia, la ambigüedad, la complejidad, lo contingente, lo no generalizable.

Es una filosofía con-formada por la transformación científico-tecnológica y cuyos ámbitos de reflexión son los que tradicionalmente se han considerado propios de las ciencias sociales, del arte y la literatura.

El análisis de la realidad presente frente a los ideales de la llustración implica investigar el cosmos urbano, su configuración, su industria y tecnología, sus actividades características, los medios de comunicación etc. porque ello nos 
permite conocer en qué presente estamos e impide que la filosofía se reduzca a mero conocimiento abstracto.

En este punto se encuentra el pensamiento de Baudrillard cuyo tema central y recurrente es el de los mass-media y sus terribles consecuencias.

\section{El movimiento del tiempo en la historia}

El tiempo real de la historia se caracteriza porque es la condición de posibilidad de la captación del sentido de los acontecimientos. La historia es significatividad de los hechos y ello exige de su tiempo, que es su elemento formal, un determinado movimiento de cambio y ritmo temporal que permita que los acontecimientos densifiquen y se hagan inteligibles sus causas, su entretejido, sus circunstancias y sus consecuencias.

Estas condiciones parece que se quiebran en nuestro mundo actual caracterizado por la aceleración en todos los ámbitos humanos: en la técnica, la política, la comunicación, la economía, la sexualidad etc., y ello se ve además reforzado por el modo en que lo que sucede se encuentra mediatizado por los medios de comunicación, los cuales transmiten unos acontecimientos instantaneizados y, lo que es más grave y como consecuencia, descontextualizados: cada acontecimiento adquiere peso propio y se pierde en sí mismo desgajado de las relaciones que le constituyen y le hacen inteligible.

Por otro lado, la inflación de la información, el exceso de comunicación y de intercambios va creando un tipo de humanidad en la que se desarrolla una indiferencia ante todo lo que ocurre, para ella los acontecimientos se van sucediendo y aniquilando en igualdad de importancia: los hechos de trascendencia social o histórica se transforman, como lo demás, en simple espectáculo. Esta mayoría hunde la historia en la actualidad, con lo que quiebra su tiempo real.

La sedimentación y distanciamiento de los hechos, así como su permanencia prolongada en el tiempo permite que los acontecimientos sean vividos como reales, sin embargo, estas condiciones se rompen también, al parecer, en el momento presente, al buscar una hiperrealidad en los medios de información. Anhelamos conocer lo que ocurre casi en el instante en que ocurre, hemos conseguido un nivel de proximidad tan grande con lo que acontece que produce el efecto contrario al deseado: la sensación de incertidumbre con respecto a la realidad de lo que acontece, ya que se nos ofrece, de nuevo, en espectáculo.

El problema es: dónde debe detenerse la información para que los acontecimientos vuelvan a ser reales. No sabemos lo que era la historia antes de que se masificaran los medios de comunicación, lo que sí sabemos es que el concepto primario de historia ha desaparecido y que ya no puede ser el mismo. iSe ha transformado? La tesis del autor es que, al desaparecer este concepto, la historia también se disuelve o desaparece. Ahora nuestra percepción del mundo y 
de la historia se nos ofrece a todos a través de los mass-media, es decir, se encuentra mediatizada por ellos, y esto sin remedio, no hay vuelta atrás.

¿Qué percepción se nos ofrece? Desde el punto de vista del tiempo, la pura actualidad, por ello carecemos de la percepción de la condensación necesaria fraguada en la duración en la que unas ideas van expresándose en hechos a través del o de los protagonistas de los acontecimientos.

La pura actualidad nos ofrece la acción pura, acciones en sentido cinematográfico, acciones que son seleccionadas por la información misma. Por ello se dan y se han dado importantes casos en que no han sido los acontecimientos los que han acarreado la información, sino que ha sido la información la que ha acarreado los acontecimientos, lo que manifiesta un trastoque de causas y efectos de consecuencias incalculables, por ejemplo la Guerra del Golfo o el proceso Ceaucescu etc.., por lo que estos acontecimientos no poseen. en realidad, el valor que socialmente se les ha conferido en libertad, democracia y derechos humanos.

Aparte de las consecuencias ya mencionadas: ausencia de sentido de los acontecimientos, poder de la información para seleccionar lo que se desea o interesa que sea real y lo que no, así como la capacidad para provocar acontecimientos importantes, tenemos que añadir que hemos perdido la sensación de que lo que ocurre es vida, hemos sustituido la vida por la representación de la vida que, como tal representación, necesariamente tiene que ser parcial y, por tanto, falseadora en cuanto al sentido.

Por otro lado, como consecuencia de la percepción presentual del mundo perdemos la memoria. El pasado como tal pierde su función de impulsarnos hacia el futuro para ser contemplado desde él como superado y por tanto, como real; de este modo la historia se disuelve, perdida la memoria cada acontecimiento se anula a sí mismo al quedarse en sí mismo: desaparece, sin más.

En el fondo nuestra época, en ese afán de instantaneidad y actualidad, está manifestando el deseo milenario de negar el tiempo lineal de la historia; este modo de vivir el tiempo se impuso, no sin esfuerzo, al tiempo cíclico y acabado de los ritos, y siempre se ha sentido engañoso porque genera espectativas del fin ilimitadamente aplazadas.

\section{La linealidad de la historia}

A partir de un determinado momento ( años 80 del s. $x x$ ) la historia llega a su punto final de linealidad. La modernidad, que ha constituido todo un proceso de liberación de pueblos, ideas, arte, inconsciente etc. ha alcanzado su limite especulativo. Hasta ese momento el espacio-tiempo de la historia era lineal, el tiempo de las luces, aquel en el que el camino más corto entre dos puntos era la línea recta de la democracia y el progreso; a partir de ese punto el espacio-tiempo lineal se curva, el tiempo se vuelve esférico y, en cuanto tal, 
pierde el futuro y el fin, es decir, la historia no continúa hacia adelante sino que se vuelve sobre ella misma.

Estamos acudiendo al fin del proceso de liberación y nos invade la necesidad de hacer una revisión de la historia en términos de nuestros referentes que son los derechos humanos, la democracia y la abolición de conflictos. Para ello llevamos a cabo un "revival" de la historia, revivimos el pasado y lo que en él ocurre para poder corregirlo desde nuestras categorías morales y jurídicas. Los nacionalismos, racismos, discriminaciones lingüísticas etc., están siendo "reciclados" construyendo con ellos una historia falsa. Por ejemplo, interpretamos publicitariamente la Revolución Francesa en términos de Derechos Humanos, olvidándola como acontecimiento real. La consecuencia es que borramos los acontecimientos en su singularidad, su sentido, su gloria y su miseria.

Nos arrepentimos de nuestra historia y tratamos de "blanquearla", sin ser, sin embargo, muy conscientes de que en el arrepentimiento se encuentra oculto el resentimiento contra el tiempo y su "fué", como diría Nietzsche, y ello es lo que nos empuja a negarlo falseándolo,"reciclándolo".

\section{La libertad en Occidente y en el Este}

Occidente se ha convertido en un basurero de la libertad y los derechos del hombre, se arroja la libertad a cambio de dinero y bienestar. Después de tanta liberación de ideas, modos, actitudes etc.. el problema de la libertad ha desaparecido porque está virtualmente resuelto, es decir, la ldea de libertad con su fuerza simbólica está muerta.

En el Este, sin embargo, la libertad ha estado congelada durante más de medio siglo, es todavía una incógnita saber cúal va a ser el destino de esta libertad en libertad. En realidad básicamente pueden ocurrir dos cosas: Puede ser que la aspiración a la libertad se cambie inmediatamente por "liquideces" occidentales, que el deseo del Este se concrete en imitar a los paises occidentales donde la libertad ha sido ya canjeada por la facilidad técnica de vivir; si esto es así, su caudal de fuerza se va a debilitar rápidamente y, lo que es peor, vamos a perder la ocasión de recuperar nuestra libertad perdida. Puede ser, sin embargo, que el Este viva empujado por la gran cantidad de libertad acumulada durante estos años, y la viva entendida como tal, con la fuerza de la Idea transformada en relaciones vivas y activas.

Esta revitalización de las acciones resultaría, no obstante, desestabilizadora para nosotros que entendemos la libertad no en el sentido de la acción sino del consenso interactivo, es decir, nuestra libertad se encuentra entre nosotros programada, operacionalizada; por eso, ante el peligro que para Occidente puede suponer la circulación de la libertad con nuevas fuerzas, ofrecemos a los paises del Este canjear la Idea de libertad por sus signos materiales. 


\section{Pérdida del pensamiento del fin}

El fin de la vida y de la historia siempre se ha sentido necesariamente como algo diferido, como lo que sucederá en un futuro y que será, a su vez, una puerta de entrada a un más allá, a una trascendencia que se encuentra después de la muerte. Esta vivencia del fín posee la función simbólica de conferir un sentido a nuestra existencia.

Frente a esta vivencia del fin nuestro tiempo está empeñado en vivirlo todo en tiempo real, en presente. Quiere la inmortalidad (es decir, la trascendencia más allá del fin) aquí y ahora, desea la realización inmediata de la inmortalidad, la inmortalidad en tiempo real.

Esta pretensión, sin embargo, es contradictoria porque la inmortalidad es un concepto que se sustrae al tiempo. El tiempo adquiere realidad en función de su término, de que termina, de su fin; sin fin, no hay tiempo. Por eso la inmortalidad en tiempo real es una irrealidad. La inmortalidad esperada es, en cambio, una ilusión que posee una función vital.

Lo mismo ocurre con la historia, también quiere ser vivida, y se vive en tiempo real cuando lo que sucede se convierte en acontecimiento presente, en información instantánea. La C.N.N. es su realización. Sin embargo ello es precisamente lo contrario de la historia.

Otro de los síntomas de la negación del fin en nuestro tiempo es el afán por retroceder hacia la génesis, hacia el principio, entendido en el sentido de la posibilidad de manipulación genética, de la determinación por el origen. De este modo la verdad se convierte en la verdad de lo que antecede. Lo que tenemos en nuestra cultura es, más que la ilusión del fin, la ilusión de la causa.

De modo que el hombre actual ante la incapacidad de resolver el problema del fin (sencillamente porque ese problema es insoluble) $y$, por lo tanto, sin haberlo resuelto, se vuelve al tiempo presente en el que pretende solucionar el problema de la inmortalidad, es decir, lo más allá del tiempo; el de la historia, que es lo temporal, sucesivo y duradero; y también el del principio, pretendiendo controlar, mediante manipulación genética, lo que el hombre es y será: es decir, pretendiendo determinar el futuro, el tiempo.

No hay lugar para el pensamiento final de nada, no hay fin concebible, ni siquiera el de la historia. Manipulamos lo del más allá del fin, la "inmortalidad técnica" sin haber pasado por la muerte: que es la operación simbólica del fin.

¿Cúal es la razón de esta pérdida del pensamiento del fin? La inmortalidad sólo se entiende como consecuencia de una concepción estable y armónica de la realidad; estabilidad, armonía y orden que proceden de la trascendencia, de la determinación de un ser superior. Así la inmortalidad es la "prolongación lógica de la continuidad de un orden". ${ }^{1}$ Pero si el orden se resquebraja enton-

1 Baudrillard. "La ilusión del fin". Barcelona. Anagrama. 1993. p. 139. 
ces todo se conmueve: el fin se vuelve problema y todo tiende a la entropía, a la degradación.La pérdida del sentido del fin se vuelve contra nosotros mismos porque, aunque tratemos de eludirlo con soluciones técnicas artificiales, Io cierto es que siempre nos es presente.

Feuerbach marca el inicio de una época que va a caracterizarse por un pensamiento dedicado a liberarse de la esclavitud de las creencias religiosas. Los pensadores posteriores, asumida la inexistencia de otro mundo más allá de este, entienden el sentido de la humanidad de tres modos distintos: como una real ización puramente individualista (Stirner); como una realización colectiva a lo largo de la historia (Marx); como una trasmutación de los valores hacia la metamorfosis del devenir (Nietzsche).

Todos estos proyectos tienden hacia una meta ideal para el hombre emancipado: una superación del hombre a sí mismo. Una ilusión, pero una ilusión noble. Nietzsche concibe la ilusión vital como la ilusión de las apariencias, del velo; es la ilusión del sentido, del significado, cuando el ser humano se siente sujeto del mundo y de la historia. El hombre sólo llega a ser sí mismo cuando asume la muerte de Dios y el consiguiente nihilismo, y entiende que sólo la vida es y es humana cuando es creadora de valores.

En contraste con este proyecto, la especie humana continúa hoy sometida a todas las supersticiones, la más importante de las cuales es, actualmente, la superstición de la psicología, la ciencia y la técnica, a la que confiere el poder de dominar la supervivencia. Hay un fetichismo técnico que se expresa en el afán de la propia domesticación a través de la manipulación biológica.

Si ha habido una trasmutación de valores no ha sido por estar más allá del bien y del mal, sino más acá. Nuestra trasmutación se orienta hacia la indiferenciación e indistinción de los valores, acompañada de una preferencia por la pluralidad de lo mínimo, de lo molecular, de la fórmula.

\section{La transformación de la especie humana en inmortal conlleva su propia destrucción}

La especie se destruye cuando lo hace su espacio vital, entendido no solamente como el entorno sino también como su espacio simbólico. Pues bien, en nuestro espacio simbólico se están resquebrajando todas las ilusiones vitales: las utopías, las ideas y el significado de los acontecimientos trascendentes de la vida,como, por ejemplo, la muerte.

Las ilusiones constituyen una parte fundamental del equilibrio simbólico de la existencia. Su actualización incondicional las destruye y, con ellas, el equilibrio vital. El hombre muere a causa de la ciencia; los signos distintivos de lo humano se van borrando porque todo se va reduciendo a una cuestión de genes, de patrimonio genético. El carácter simbólico de la muerte-inmortalidad se está transformando en una cuestión de código biológico. 
Lo mismo ocurre en psicología, el alma muere disuelta en el proceso de análisis del mundo interno, de la misma manera que la ciencia anátomica supone la muerte del cuerpo. En este contexto, la muerte como metáfora se transforma en realidad y fatalidad biológica. Este es el escenario de la verdad objetiva de la ciencia: en él se confunden los límites entre lo humano y lo inhumano.

El humanismo ilustrado se construyó sobre una concepción del ser humano basada, ante todo, en su dignidad, autonomía, libertad e inteligencia; actualmente la preocupación por el hombre se centra, sobre todo, en su conservación, tanto individual como de la especie Ello se expresa muy bien en los derechos humanos.

Sin embargo los propios derechos del hombre plantaen problemas éticos conforme avanza la investigación biogenética: ¿tiene una especie derecho sobre su propia definición genética?, es decir ¿tiene una especia derecho sobre sí misma como para decidir su propia conservación o desaparición?

La ciencia y la técnica constituyen la nueva religión, la fé en el poder de la investigación científica para alcanzar el tipo de hombre que se desea, nos conduce a llevar a cabo un reduccionismo antropológico que estrecha y empobrece la concepción del ser humano. Entender al hombre en términos de biología encierra el gran peligro de confundir los límites que separan lo humano de lo inhumano. Decir que el hombre es lo que lleva inscrito en su herencia genética y que será lo que permita la manipulación de sus genes es aniquilar su definición: la que se apoya en su condición de hombre libre.

El ultramundo de antes compuesto de Dios, alma e inmortalidad era una ilusión, una proyección de las facultades humanas en un mundo sobrehumano, era una ilusión inmaterial de gran poder vital y fuerza proyectiva que generaba importantes espectativas para la existencia.

En este momento vivimos también de una ilusión pero destructiva. Hundidos en la biología y la genética nos encontramos en la pura materialidad: alcanzaremos la inmortalidad porque estamos compuestos de elementos nucleares indestructibles; no hay lugar para el alma inmortal supratemporal; también el cuerpo se desvanece disuelto en las funciones de lo vivo; y desaparece la ilusión del pensamiento sustituido por la inteligencia artificial.

La muerte tiene una importante función en el hombre: el protagonismo del morir, el acontecimiento fundamental y determinante de la vida al modo humano. En estos momentos vamos en camino de crear procesos de vida indestructibles y, con ellos, exterminar la muerte. Captamos la inmortalidad en los procesos anatómicos, biológicos y genéticos. A esta inmortalidad estamos condenados sin quererlo porque es una inmortalidad, no en razón del alma, que ha desapareciso, ni del cuerpo, en trance de desaparecer, sino en razón del código y la fórmula. 
La muerte era la conquista más hermosa del hombre: la muerte subjetiva, dramatizada, ritualizada, buscada y deseada, es lo que más diferencia al ho mbre de otras especies animales. Por eso, este tipo de inmortalidad formularia, genética, es el peor de todos los destinos.

Antes se pensaba que la inmortalidad pertenecía al más allá, a un trasmundo; ahora la inmortalidad es de este mundo, que por eso se transforma en tr asmundo real, en el lugar de la "superstición total".

\section{Conclusión}

La ciencia y la tecnología, creadoras de instrumentos que potencian la capacidad del ser humano para penetrar en la realidad, hacen posible el descubrimiento de nuevas perspectivas y dimensiones antes desconocidas, y ello va transformando nuestra cosmovisión, va cambiando la idea acerca de la configuración de nuestro mundo, tanto exterior como interior, y, por consiguiente, también se transforma nuestro modo de referirnos a él.

Junto con el descubrimiento de nuevas dimensiones, aparece el descubrimiento de nuevas posibilidades de control y transformación, y éstas, a su vez, nos plantean nuevos e importantes problemas éticos ¿Hasta dónde es éticamente correcto intervenir en la alteración y producción genética? Las posibilidades son inmensas y los debates a que dan lugar también lo son.

Por otro lado, el avance de la ciencia y de la técnica y sus consecuencias es imparable. Parece ser un fenómeno que, si en un momento de la historia nació bajo la iniciativa y el dominio del hombre, en estos momentos está por encima de nuestras posibilidades de control. No tenemos tecno-ciencia sino que la tecno-ciencia nos tiene y está orientando nuestro destino, nuestra trayectoria vital, económica, social, política e histórica.

Este nuevo modo de ser-en-el-mundo se caracteriza porque en él se transforman nuestros referentes de la realidad:

- La ciencia y la técnica han dejado de ser consideradas como agentes de progreso; en su lugar son vividas como amenaza, la más terrible: la de la extinción de la especie; o la de posibilitar algo así como el profético "mundo feliz" de Huxley mediante el control genético de la especie humana.

- Tampoco es posible ya la consideración del sujeto dueño de su propia h istoria; protagonista de su proceso liberador, a través de una conquista progresiva de su autoconciencia, y de la construcción racional de su mundo. Si de algo es consciente el hombre actual es de que es irremediable e irreversiblemente manipulado por los medios de comunicación social, al servicio de intereses económicos y políticos; y que su mundo le exige su ser a cambio de tener. 
- El ideal Ilustrado de la Razón, que se legitima y justifica a sí misma, se ha transformado, en el mejor de los casos, en una razón "situada", en el peor, en una jaula de hierro de la que no se puede escapar.

En nuestra sociedad la tecnología no es un factor más de lo social, sino una manera de ser-en-el-mundo del hombre y una manera de ser mundo el mundo, de tal forma que lo que parece encontrarse bajo el poder del hombre, en realidad es una estructura que se le impone. La técnica pasa a ser el componente esencial de la sociedad, determinante de creencias, ideas y forjadora de mitos. Es la emergencia de un nuevo tipo de humanidad. 